\title{
Oil Prices and Financial Markets Activity: Empirical Evidence from Some MENA Countries
}

\author{
Marwan Al-Nahleh (Corresponding author) \\ Department of Financial Management, Jerash Private University - Jordan \\ P.O. Box 6029Amman11118Jordan \\ E-mail:marwanalnahleh@gmail.com
}

Khaled Al-Zaubia

Department of Banking and Finance, the Hashemite University

P.O. Box 150459Alzarqa13115Jordan

E-mail:alzubik@gmail.com

Received: November 6, 2010 Accepted: January 7, 2011 doi:10.5539/ibr.v4n2p193

\begin{abstract}
This study assesses empirically the effects of oil prices on financial markets activity of some MENA countries (Middle East \& North Africa).We have chosen this subject to study aiming to find out and explain if there is a relationship between international oil prices and the prices of the listed securities in the financial markets of Middle East and North Africa. The countries that will be in the sample of analysis are Turkey, Jordan, Egypt, Morocco, Tunis, we targeted these countries of this geographical area based on specific characteristics of these countries as they are oil importers; in the meantime they have sharing borders with big oil exporting countries.
\end{abstract}

Keywords: Energy Shocks, vector auto regression (VAR), MENA countries (Middle East \& North Africa), Lead-Lag Correlations, International oil price.

\section{Introduction}

\section{Oil prices and Stock Markets}

The stock market long has been viewed as an information collection and processing institution. The asset prices establishment depends on information about future prospects as well as current conditions facing firms. The efficiency with which stock markets process information has been a subject of intensive study for several decades. If stock-price or rate-of-return forecasts cannot be improved upon by use of any other information, the case can be made that the stock market is already using all publicly and privately available information in the formation of those prices. It is reasonable to expect that the stock market would absorb the information about the consequences of an oil price shock and incorporate it into stock prices very quickly. Since asset prices are the present discounted value of the future net earnings of firms, both the current and the future impacts of such a shock should be absorbed into prices and returns without having to wait for those impacts to actually occur.

The literature of theoretical and empirical studies on oil prices and Stocks Markets relationship is very tide, maybe due to the short life of oil prices Fluctuations, where the benchmark of these fluctuations in the previous century is the October 1973 Arab-Israeli war and the accompanying embargo of oil shipments to the U.S. by OPEC nations which dramatically changed the oil market.

Another oil price shock in 1979, which followed the Iranian revolution when spot oil prices rose sharply, the recent oil price shock is formulated by the invasion of Iraq by the U.S. army and still osculated with the tension of Iranian-Western World relations because of the Iranian nuclear program and the probability of military conflict in the Arab Golf area which will endanger oil supplies. Third wave of fluctuations is the most recent one that starts from the med of 2003 till the end of 2006.

Never the less, there are some important studies that took this relationship under analysis, one is by Roger D. Huang \& others "Energy Shocks and Financial Markets (1995)" they examined the contemporary and lead-lag correlations between daily returns of oil futures contracts and stock returns. Their analysis was at three levels; first, for a market stock price index S\&P 500 index; second, for 12 stock price indices; third, for three individual oil 
company stock price series. The vector autoregressive (VAR) approach is used to examine the lead-lag relation, and its results showed that oil futures returns are not correlated with stock market returns, even contemporaneously, except in the case of oil company returns.

Another important study by Cetin Ciner "Energy Shocks and Financial Markets: Nonlinear Linkages (2002)" using same approach of analysis of VAR models and Granger causality tests, to test linear and nonlinear linkages between oil prices and stock prices highlighting the possibility of nonlinear linkages between oil prices and stock prices. Ciner demonstrates a significant nonlinear causal correlation between crude oil futures returns to S\&P 500 index returns and evidence that stock index returns also affect crude oil futures. This indicates a feedback relation between S\&P 500 stock returns and crude oil futures.

Different approach applied by Gerben Driesprong, Ben Jacobsen, \& Benjamin Maat in their paper " Stock Markets and Oil Prices (2004) " testing for the existence of an oil-effect they used the usual regression techniques and incorporated an oil-variable roilt-1 in the regression:

$r t=\mu+\alpha 1 r^{o i l} t-1+\varepsilon 1 \quad$ with $\varepsilon t=r t-E t-1[r t]$

Where $\mu$ is a constant and $\varepsilon 1$ the usual error term, using the above equation they tested whether the coefficient of roilt-1 is significantly different from zero. When $\alpha 1$ is significant, this rejects the null hypothesis of no oil effect. From the previous equation the absence of an oil-variable this equation reduced to the well-known random walk model.

"Oil Price Risk and Emerging stock Markets" by Syed A. Basher and Perry Sandusky, they introduced another approach of studying oil Prices Stock Markets relationships by using an international multi-factor (Arbitrage Pricing Theory APT Model), The model estimation follows a two-step process.

In the first step, country stock market betas, oil price betas, and exchange rate betas are estimated using ordinary least squares (OLS) from the following multi-factor model:-

$$
\text { Rit }=c+\beta m i t M R t+\beta o i t O I L t+\beta e i t T W E X t+\varepsilon i t .
$$

In equation (1) the country excess returns are Rit ( $\mathrm{i}=1 \ldots 21$ denotes the country and denotes the time period), world market excess returns are MRt, oil returns are OILt, and exchange rate returns are TWEXt.

In the second step, unconditional and conditional cross section regressions are estimated for a pooled data set of realized stock returns and risk parameters. Betas from period $t$ are matched with realized stock returns from period $\mathrm{t}+1$.

$$
\text { Rit }=\gamma 0+\gamma m 1 \beta m i t+\gamma o 1 \beta o i t+\gamma e 1 \beta e i t+\varepsilon 2 t .
$$

The market betas, oil betas, and exchange rate betas are estimated from equation (1). Equation (2) specifies an unconditional relationship between returns and risk that is estimated using pooled OLS.

There are some limitations in implementing multi-factor model to study this relationship such as both the CAPM and APT models assumed that expected returns, risk factors and risk premiums are linearly related which it is not a must.

A recent study by George Bittlingmayer "Oil and Stocks: Is it War Risk? (2005)" Using simple regression technique by combining the percentage changes in the value-weighted stock price index on percentage changes in oil prices (West Texas Intermediate) for the period 1983-2004.

In a recent study by Dawid Brychcy "The impact of oil prices on international financial markets (2006)" the researcher evaluates the influence of the returns on the oil prices on international financial markets. Using the family of GARCH models (both univariate and multivariate) he assesses the effects from the changes in the oil prices to the main stock markets in the world. In his analysis he include the returns on the DJIA, S\&P 500, NASDAQ, FTSE 100, DAX, NIKKEI 225 and the returns on the WTI crude price. The results show that oil prices have impact on all the stock markets but this influence takes different forms. He has obtained that only DJIA and S\&P500 directly react to the changes in returns on oil prices. This impact is negative and very low. There are no asymmetric effects of the changes of oil prices on the stock markets and already one day lag does not have any influence more. The returns on American stock markets are influenced by the volatility of oil prices as well and this effect seems to be more significant.

The traditional definition of Stock prices is the discounted values of expected future cash flows. Oil prices can affect both the expected cash flows and discount rates for different reasons. Oil prices affect future cash flows as an important input in the production process. The increasing oil prices raise the cost of production and lower benefits of the companies - this effect depends on whether the company is a net producer or net consumer of oil. 
Oil prices can affect the stock prices through the discount rates because the expected discount rate is the sum of the expected inflation rate and expected real interest rate, both of which may in turn depend on oil prices.

From this literature review the methodology of research to study Oil and Stock prices relationships is confirmed to be in two analytical framework, the first is by using simple Regression Techniques (multi factor models) and the other one is more sophisticated by using VAR models and Granger causality tests which we think that this methodology is more reliable to clarify such relations in a good manner.

This paper is organized as follows. Section 2 describes the data and methodology. Section 3 reports the empirical results of tests for the correlation structure between main indices that are calculated and published by the stock market authority and one of the main indicators for international oil prices. The last section concludes the paper.

\section{Data and Methodology}

In this study we exploit the daily closing price of the Europe Brent Spot Price FOB which considered as worldwide main indicator of oil price and used by most studies as a proxy for International Oil Prices, and time series of daily closing prices for the general index calculated and published by the stock exchange authority in each country included in the analyses which are (Morocco, Tunisia, Egypt, Jordan, and Turkey), the time series starts from 1 January 2004 to 31 December2006.

\subsection{Data}

- Data base of this study which will be used in the analysis consist of two categories:

- Time series of daily closing prices for the general index calculated and published by the stock exchange authority in each country included in the analyses which are (Morocco, Tunisia, Egypt, Jordan, and Turkey), the time series starts from 1/1/2004 to 31/12/2006, with an average of 740 observations.

- There are many price indicators of international oil price some considered as regional rather than worldwide indicators, while others depend on output (pricing) of more mature markets. In general, the most appropriate and used as a proxy for international oil prices are Brent Blend United Kingdom and West Texas United States, because of the pricing mechanism that produces those prices which relay on many reasonable economic and financial factors, also most of literature relay on these two price indicators as a proxy for oil factor in the analysis. While WTI (West Texas of the United States) pricing system is affected by some other factors of financial and economical like political and natural factors. So it is more convenient to use crude oil price time series that produced by Brent Blend of the United Kingdom pricing system which by the way have no major differences from that of West Texas of the United States pricing system, which both relay on too many market factors with a great role to demand-supply pricing mechanism. The time series related to the closing prices of international crude oil is the closing prices of Brent Blend of the United Kingdom and for the same time period from 1/1/2004 to 31/12/2006.

Data consist of daily closing prices of international oil are obtained from the U.S. Department of Energy database and the daily closing prices of the general index calculated and published by the stock exchange authority in each country included in the analyses which are (Morocco, Tunis, Egypt, Jordan, and Turkey), the time series start from 1/1/2004 to 31/12/2006, Financial markets indices are in local currency of each country, oil prices are in U.S. dollars.

In the analysis the prices are expressed as:

IOP: international oil price

$\mathrm{IOP}_{\mathrm{t}}=$ return of international crude oil at time $\mathrm{t}$

FMA: financial market activity that will be measured by index (INDX) and expressed by this equation:

$\mathrm{FMA}_{\mathrm{kt}}=$ return of main index of country $\mathrm{k}$ at day $\mathrm{t}$

The issue of determining the appropriate sampling frequency is not standardized in the literature of finance. Never the less, the sample size in this study is considered to be comprehensive and convenient with a good time coverage that suits the purpose of this study.

\subsection{The Applied Methodology}

\section{Correlation structure}

In this section of the paper the study investigates of the short-and long-term relationships between MENA countries financial markets and international crude oil. Limited studies had been made on the financial markets activity linking it to several financial and economical factors. This study aims to fill this gap by investigating the short and long-term relationships between financial markets in some MENA countries and international crude oil prices. 
This study expects at least one market would be affected by international oil prices fluctuations, if they are found to be co integrated. it means that past values of international oil prices can be used to predict the future stock market index or vice versa.

- Cross-correlation

- 5 Days lag correlation

- The VAR framework

1. Cross-correlation

The first step in the analysis examines the correlation of all time series under analysis by introducing the correlation matrix.

2. led-lag correlations

5 Days lag correlations were estimated by regressing the current return of financial market $\mathrm{k}$ time series on international oil current and prior five days' returns, that is, the following regression was estimated:

$r_{t}^{k}=\alpha_{0}{ }^{+} \alpha_{1} r_{t}^{\text {oil }}+\alpha_{2} r_{t-1}^{\text {oil }}+\alpha_{3} r_{t-2}^{\text {oil }}+\alpha_{4} r_{t-3}^{\text {oil }}+\alpha_{5} r_{t-4}^{\text {oil }}+\alpha_{6} r_{t-5}^{\text {oil }}+\varepsilon_{t}$

Where

$r_{i}^{k}$ is return of financial market $\mathrm{K}$ at time $\mathrm{t}(\mathrm{k}=1 \ldots . .5)$.

$r_{t-i}^{\text {oil }}$ is return of International oil market at time $\mathrm{t}-\mathrm{i}(\mathrm{i}=0,1 \ldots .5$ Days $)$

1. The VAR framework

Using vector auto regression (VAR) system which is commonly used for forecasting systems of interrelated time series and for analyzing the dynamic impact of random disturbances on the system of variables, I'll analyze the dynamic of correlation between each stock market index and oil prices separately, which is the same econometric model approach that partially applied by Cetin Ciner (2001) and totally by Roger D. Huang, Ronald W. Masulis, Hans R. Stoll (1995) and expressed by these equations:

$$
\begin{aligned}
& \mathrm{FMA}_{\mathrm{t}}=\alpha+\sum_{i=1}^{m} \beta_{i} I O P_{t-i}+\sum_{j=1}^{m} \lambda_{j} F M A_{t-j}+\varepsilon_{t} \\
& \mathrm{IOP}_{\mathrm{t}}=\delta+\sum_{j=1}^{m} \psi_{j} F M A_{t-j}+\sum_{i=1}^{m} \mu_{i} I O P_{t-i}+\omega_{t}
\end{aligned}
$$

\section{Econometric Results}

\section{Data base tests Results (The characteristics of market)}

\section{Descriptive Statistics}

This section considers the empirical characteristics of returns in the capital markets under analysis which are international oil market and some financial markets at MENA area which are Morocco, Tunisia, Egypt, Jordan, and Turkey financial markets.

\section{Insert Table 1 Here}

Concerning the main descriptive statistics, I observe that the returns in international oil market were characterized by the highest standard deviation, so the volatility of oil prices was the biggest one among all the series of returns under consideration. The value of the Skewness in Turkey, Egypt, and Casablanca is negative which shows that the returns are left-skewed and the kurtosis in the case of the returns is much smaller than in the case of the series of levels which indicates thin tails in the distribution. Those are the common stylized facts observed in the series of returns on capital markets.

For each of the series of returns I have performed the Jarque-Bera test for the null hypothesis at $5 \%$ level of significance which allows me to reject the null hypothesis about normality. The Jarque-Bera test shows that the returns do not have the normal distribution.

\section{Correlation Structure Results}

As a first step towards exploring the bilateral effects of oil price changes and some MENA financial markets returns, I'll introduce the correlation matrix as a primary indicator for the bilateral relationship between all-time series under analysis. This simple analysis can be used as guidance through the advanced statistical analysis process. 


\section{Cross-correlation}

Introducing the correlation matrix as a simple statistical analysis which shows the strength and direction of relationship between two variables, from the table below (Table 9) all time series are positively related while the strength of the relation vary in a wide difference, the weakest one is that between Jordan and Casablanca financial markets (0.389440), the strongest is between Tunis and Casablanca (0.956215) which consistent with the fact that both Tunis and Casablanca are highly correlated due to the geographical and structural similarities between these two markets.

Nevertheless the main benefit from this analysis is by giving a preliminary indicator about how each two factors are moving together, without making further clarification about the time span of bilateral effects, the direction of the relationship (which factor cause the other).......etc. all these questions will be answered in the next advanced level of statistical analysis.

Insert Table 2 Here

\section{Lead-lag correlations}

5 Days lag correlations were estimated by regressing the current return of financial market $\mathrm{k}$ on international oil market current and prior five days' returns, that is, the following regression was estimated:

$r_{t}^{K}=\alpha_{1} r_{t}^{o i l}+\alpha_{2} r_{t-1}^{o i l}+\alpha_{3} r_{t-2}^{o i l}+\alpha_{4} r_{t-3}^{o i l}+\alpha_{5} r_{t-4}^{o i l}+\alpha_{6} r_{t-5}^{o i l}+\varepsilon_{t}$

Where

$r_{t}^{k}$ is return of financial market $\mathrm{K}$ at time $\mathrm{t}(\mathrm{k}=1 \ldots . .5)$.

$r_{t-i}^{o i l}$ is return of International oil market at time $\mathrm{t}-\mathrm{i}(\mathrm{i}=0,1 \ldots .5$ Days $)$

\section{Casablanca and oil 5 Days lag correlations}

5 Days lag correlations were estimated by regressing the current returns of Casablanca financial market on international oil market current and prior five days' returns, that is, the following regression was estimated:

$r_{t}^{C S E}=\alpha_{1} r_{t}^{\text {Oil }}{ }_{+} \alpha_{2} r_{t-1}^{\text {Oil }}+\alpha_{3} r_{t-2}^{\text {Oil }}+\alpha_{4} r_{t-3}^{\text {Oil }} \alpha_{5} r_{t-4}^{\text {Oil }} \alpha_{6} r_{t-5}^{\text {Oil }}+\varepsilon_{t}$

Where

CSE

$r_{t}$ : Daily returns of general index of Casablanca Stock Exchange (Casablanca Financial Market).

By applying Ordinary Least Squares test to explore the bilateral relation between each financial market and international oil market with 5 Days lags. This model of analysis has produced the following equation:

$r_{t}^{\text {CSE }}{ }_{=-0.0239} r_{t}^{\text {Oil }}{ }_{+0.0011} r_{t-1}^{\text {Oil }}{ }_{-0.0662} r_{t-2}^{\text {Oil }}{ }_{-0.0137} r_{t-3+0.0168}^{\text {Oil }} r_{t-4}^{\text {Oil }}{ }_{-0.0962} r_{t-5}^{\text {Oil }}+\boldsymbol{\varepsilon}_{t}$

From the previous equation I can notice that:

1. CFM (Casablanca Financial Market) returns are negatively related with IOM (International Oil Market) returns at the same day of trading in both capital markets.

2. Returns in CFM are positively related with returns of IOM for previous, the past fourth trading days (T-1, T-4).

3. Returns in CFM are negatively related with returns of IOM for trading days (T-2, T-3, and T-5).

Egypt and oil 5 Days lag correlations

The same statistical model was applied for returns of both (EFM) Egypt Financial Market and IOM; the regression equation was as follow:

$r_{t}^{\text {CASE }}=0.06520{ }_{t}^{\text {Oil }}-0.016081 r_{t-1}^{\text {Oil }}+0.070252 r_{t-2}^{\text {Oil }}-0.010973 r_{t-3}^{\text {Oil }}{ }_{0.058741} r_{t-4}^{\text {Oil }}-0.001823{ }_{t-5}^{\text {Oil }}+\varepsilon_{t}$

Where

$r_{t}^{\text {CASE }}$ : Daily returns of general index of Cairo and Alexandria Stock Exchange (Egypt Financial Market).

From the previous equation I can notice that:

1. (EFM) Egypt Financial Market returns are positively related with IOM (International Oil Market) returns at the same day of trading in both capital markets.

2. Returns in EFM are also positively related with returns of IOM for trading days (T-2). 
3. Returns in CFM are negatively related with returns of IOM for trading days (T-1, T-3, T-4, and T-5).

Jordan and oil 5 Days lag correlations

The regression equation for Jordan Financial Market (JFM) and IOM returns was as follow:

$r_{t}^{\text {ASE }}{ }_{=-0.021723} r_{t}^{\text {oil }}{ }_{+0.018090} r_{t-1+0.029083}^{\text {Oil }} r_{t-2+0.004927}^{\text {oil }} r_{t-3}^{\text {Oil }}{ }_{-0.036395} r_{t-4}^{\text {Oil }}{ }_{-0.043668} r_{t-5+}^{\text {oil }} \varepsilon_{t}$

Where

$r_{t}^{A S E}$ : Daily returns of general index of Amman Stock Exchange (Jordan Financial Market).

From the previous equation I can notice that:

1. (JFM) Jordan Financial Market returns are negatively related with IOM (International Oil Market) returns at the same day of trading in both capital markets.

2. Returns in JFM are also positively related with returns of IOM for trading days (T-1, T-2, and T-3).

3. Returns in JFM are negatively related with returns of IOM for trading days (T-4, and T-5).

4. Tunis and oil 5 Days lag correlations

In accordance to Tunis stock exchange the 5 days lag regression results were as follows:

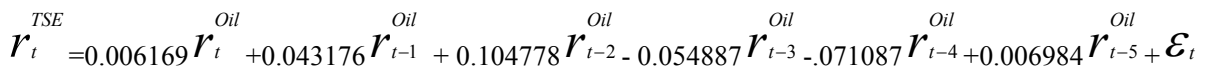

From the previous equation I can notice that:

1. (TSE) Tunis Financial Market returns are positively related with IOM (International Oil Market) returns at the same day of trading in both capital markets.

2. Returns in TSE are also positively related with returns of IOM for trading days (T-1, T-2, and T-5).

3. Returns in TSE are negatively related with returns of IOM for trading days (T-3, and T-4).

\section{Turkey and oil 5 Days lag correlations}

For turkey Financial Market correlation with 5 days lag of IOM there was same behavior with that of other financial markets under consideration, the following equation was the result of regressing lagged oil returns on turkey financial market returns:

$r_{t}^{I S E}=\mathbf{0 . 0 0 6 1 6 9} r_{t}^{\text {Oil }}+\mathbf{0 . 0 4 3 1 7 6} r_{t-1}^{\text {Oil }}+\mathbf{0 . 1 0 4 7 7 8} r_{t-2}^{\text {Oil }} \mathbf{- 0 . 0 5 4 8 8 7} r_{t-3}^{\text {Oil }} \mathbf{- 0 . 0 7 1 0 8 7} r_{t-4}^{\text {Oil }}+\mathbf{0 . 0 0 6 9 8 4} r_{t-5}^{\text {Oil }}+\varepsilon_{t}$

Where

$r_{t}^{I S E}$ : Daily returns of general index of Istanbul Stock Exchange (Turkey Financial Market).

From the previous equation I can notice that:

1. (TFM) Turkey Financial Market returns are positively related with IOM (International Oil Market) returns at the same day of trading in both capital markets.

2. Returns in TFM are also positively related with returns of IOM for trading days (T-1, T-2, and T-5).

3. Returns in TFM are negatively related with returns of IOM for trading days (T-3, and T-4).

\section{Gross Summary of Lead-Lag Correlations}

From the previous results I can notice that there is a pattern of financial markets behavior towards the international oil market returns, this pattern indicate that investors (especially oscillators) are maneuvering from financial market to oil market on a daily bases and any new investor have intention to invest or oscillate in these financial markets should put under his consideration the behavior of returns in International Oil Market.

\section{The VAR framework}

The VAR model takes account of the simultaneous interaction of the time series of International Oil Market Returns and some MENA Financial Markets Returns. Let IOP be International Oil Market Returns, let FMA be one of 5 MENA Financial Markets Returns. The VAR representation can be expressed as a two equation system:

$$
\begin{gathered}
\mathrm{FMA}_{\mathrm{t}}=\alpha+\sum_{i=1}^{m} \beta_{i} I O P_{t-i}+\sum_{j=1}^{m} \lambda_{j} F M A_{t-j}{ }^{+} \varepsilon_{t} \\
\mathrm{IOP}_{\mathrm{t}}=\delta+\sum_{j=1}^{m} \psi_{j} F M A_{t-j}+\sum_{i=1}^{m} \mu_{i} I O P_{t-i}+\omega_{t}{ }^{*}
\end{gathered}
$$


The approach is to estimate the system of equations, (a) and (b) and to test a series of hypotheses about the lead-lag relation of some MENA Financial Markets returns and International Oil Market returns. The important benefit of the VAR system (a) and (b) is that it controls for factors such own serial correlation. It is also possible to distinguish one-way leads or lags from feedback relations.

The null hypothesis that International Oil Market Returns do not lead some MENA Financial Markets Returns can be stated in the context of the VAR model as:

$$
H^{l} 0: \beta_{i}=0 \quad, \quad(\mathrm{i}=1 \ldots .5)
$$

The likelihood ratio under the null is asymptotically distributed as chi-square. The null hypothesis that some MENA Financial Markets Returns do not lead International Oil Market Returns can be stated in the context of the VAR model as:

$$
H^{2} 0: \psi_{j}=0 \quad, \quad(\mathrm{j}=1, \ldots \ldots . .5)
$$

An F-test can be used to examine the exclusion restrictions in (B).

\section{Leads and lags in returns}

The VAR model estimates for the various time series of returns are presented in the Table below. The results for H10 are very interesting which express the rejection of the null hypothesis of that oil does not lead MENA Financial Markets for all financial markets under consideration, while for F-statistics test parameters show the acceptance of H20 that MENA Financial Markets do not lead oil prices changes.

VAR Tests of Granger Causality between Returns on International Oil Markets and MENA Financial Markets Insert Table 3 Here

So for any investor who is trading in financial markets under analysis should follow up the changes in International Oil prices not just for quick swings but especially for slow long motion. The main clarification for these results is related (in my point of view as a financial consultant in three of the five financial markets under analysis) is directly consistent with the strategies of trading and investment of international cash flow especially for excess liquidity in the Gulf area that seeks for profitable, secure, and above all the flexibility of cash flow from and to the final destination of cash.

\section{References}

Kamal A. Al-Qudah. (1997). An Empirical Testing of the Randomness Hypothesis in Amman Financial Market, Dirasat, Administrative Sciences, 24, No.2.

A.Yuce and C. Sigma-Mugan. (1996). An Investigation of the Short- and Long-Term Relationships between Turkish Financial Markets, the European Journal of Finance, 2, pp. 305-317.

Bwo-Nung Huang, Chin-Wei Yang \& John Wei-Shan Hu. (2000). Causality and Cointegration of Stock Markets among the United States, Japan, and the South China Growth Triangle, International Review of Financial Analysis, 9:3, pp.281-297.

Wilson H.S. Tong. (2001). Cointegration, Efficiency and Forecasting in the Currency Market, Journal of Business Finance \& Accounting, 28(1) \& (2). 0306-686x.

Paul A. Volcker. (1975). Inflation, Recession, Oil, and International Financial Markets, Journal of International Affair, 9, No.1.

Cetin Ciner. (2001). Energy Shocks and Financial Markets: Nonlinear Linkages, Studies in Nonlinear Dynamics and Econometrics, 5(3): pp.203-212.

Joshua M. Pollet. (2002). Predicting Asset Returns With Expected Oil Price Changes, Journal of Business Finance \& Accounting, 21(1). pp 112-143.

Gerben Driesprong, Ben Jacobson \& Benjamin Maat. (2003). Stock Markets and Oil Prices, Working Paper.

Syed A. Basher, Perry Sadorsky. (2005). Oil Price Risk and Emerging Stock Markets, Working Paper.

Bernd Hayo \& Ali M. Kutan. (2005). The Impact of News, Oil Prices, and Global Market Developments on Russian Financial Markets, Economics of Transition, 13(2). pp.373-393.

Dawid Brychcy. (2006). The Impact of Oil Prices on International Financial Markets, Working Paper.

Roger D. Huang, Ronald W. Masulis \& Hans R. Stoll. (1995). Energy Shocks and Financial Markets. Working Paper. 
Daniel B. Thornton \& Michael Welker. (1999). Impact of Market Risk Disclosures on Stock Price Sensitivity to Oil and Gas Prices.

Stephen P. A. Brown, Mine K. Yucel \& John Thompson. (2003). Business Cycles: The Role of Energy Prices.

George Bittling Mayer. (2005). Oil and Stocks: Is it War Risk?

Kim R. Sawyer \& Mohan Nandha. (2005). How Oil Moves Stock Prices.

Sridhar Gogineni \& Michael F. Price. (2006). The Stock Market Reaction to Oil Price Changes.

Christopher Gan, Minsoo Lee, Hua Hwa Au Yong \& Jun Zhang. (2006). Macroeconomic Variables and Stock Market Interactions: NEW ZEALAND Evidence, Investment Management and Financial Innovations, Volume 3, Issue 4.

Table 1. The main statistics of the data

\begin{tabular}{|l|l|l|l|l|l|l|}
\hline & Oil & Casablanca & Egypt & Jordan & Tunis & Turkey \\
\hline Mean & 0.00117418 & 0.00128427 & 0.00256861 & 0.00117389 & 0.00071537 & 0.00113078 \\
\hline Median & 0.00087655 & 0.00132538 & 0.00229638 & 0.00096817 & 0.00050627 & 0.00225732 \\
\hline Maximum & 0.12152309 & 0.05721414 & 0.07072783 & 0.08721377 & 0.02743527 & 0.05869820 \\
\hline Minimum & -0.06986821 & -0.04892967 & -0.07617046 & -0.07205074 & -0.01385887 & -0.08305536 \\
\hline Std. Dev. & 0.02123935 & 0.00902663 & 0.01795082 & 0.01509983 & 0.00528298 & 0.01730020 \\
\hline Skewness & 0.30526074 & -0.12221322 & -0.22669678 & 0.01195026 & 0.50571429 & -0.27769700 \\
\hline Kurtosis & 4.79687733 & 8.59658848 & 5.07939562 & 5.54385006 & 4.98833786 & 3.85401746 \\
\hline & & & & & & \\
\hline Jarque-Bera & 47.11275 & 92.21483 & 86.45676 & 76.49738 & 88.71273 & 51.46588 \\
\hline Probability & 0.000000 & 0.000000 & 0.000000 & 0.000000 & 0.000000 & 0.000000 \\
\hline & & & & & & \\
\hline Observations & 741 & 741 & 741 & 741 & 741 & 741 \\
\hline
\end{tabular}

Table 2. Correlation matrix of 6 capital markets included in the analysis.

\begin{tabular}{|lcccccc|}
\hline & OIL & CASABLANCA & EGYPT & JORDAN & TUNIS & TURKEY \\
OIL & 1.000000 & 0.742972 & 0.853658 & 0.739412 & 0.760066 & 0.826535 \\
\hline CASABLANCA & 0.742972 & 1.000000 & 0.751994 & 0.389440 & 0.956215 & 0.813814 \\
\hline EGYPT & 0.853658 & 0.751994 & 1.000000 & 0.859753 & 0.748198 & 0.946995 \\
\hline JORDAN & 0.739412 & 0.389440 & 0.859753 & 1.000000 & 0.425298 & 0.750307 \\
\hline TUNIS & 0.760066 & 0.956215 & 0.748198 & 0.425298 & 1.000000 & 0.759077 \\
\hline TURKEY & 0.826535 & 0.813814 & 0.946995 & 0.750307 & 0.759077 & 1.000000 \\
\hline
\end{tabular}

Table 3. The VAR model estimates for the various time series of returns.

\begin{tabular}{|c|c|c|c|c|}
\hline \multirow{2}{*}{ MENA Financial Markets } & \multicolumn{3}{|c|}{ International Crude Oil } \\
\cline { 2 - 5 } & $H^{l} 0:$ Oil does not lead MENA Financial & \multicolumn{2}{c|}{$H^{2} 0:$ MENA Financial Markets do not lead oil } \\
\cline { 2 - 5 } & $\chi^{2}$ & P-Value & F-Statistics & P-Value \\
\hline Casablanca Stock Exchange (CSE) & 4282.750 & 0.000959 & 0.511214 & 0.001077 \\
\hline Cairo and Alexandria Stock Exchange & 3739.033 & 0.002222 & 1.738990 & 0.000904 \\
\hline (CASE) & 3870.797 & 0.001212 & 0.687087 & 0.000972 \\
\hline Amman Stock Exchange & 4655.941 & 0.000584 & 0.789911 & 0.000940 \\
\hline Tunis Stock Exchange & 3761.526 & 0.001088 & 0.486687 & 0.001019 \\
\hline Istanbul Stock Exchange & & & & \\
\hline
\end{tabular}

